\title{
LA CELESTINA Y EL TEATRO DEL SIGLO XVI*
}

\author{
Miguel Ángel Pérez Priego
}

UNED

Las imitaciones de La Celestina - la llamada celestinesca o descendencia directa - constituyen un campo de estudio bien delimitado por la historia literaria, que cuenta con aportaciones tan decisivas como las de Menéndez Pelayo, María Rosa Lida de Malkiel, Marcel Bataillon o Pierre Heugas'. El teatro, las imitaciones teatrales no han recibido, en cambio, una atención semejante, aunque en aquellos trabajos no deje de haber continuas y sugerentes referencias, aparte la existencia de algún estudio sobre autores y obras particulares. Nuestro propósito es intentar aquí un primer acercamiento a ese problema crítico del influjo de La Celestina en el teatro posterior.

El teatro castellano del siglo XVI es, en buena medida, una sucesión de tanteos y de ensayos en busca de una fórmula dramática, la cual ciertamente sólo se verá alcanzada con la comedia de Lope de Vega y de su época. En esa búsqueda, La Celestina supuso siempre un formidable estímulo literario y un frecuentísimo punto de referencia, lo que igualmente podriamos decir

* Las presentes páginas fueron leídas como ponencia presentada en las Jornadas sobre Teatro Clásico ("La Celestina: texto y representación dramática»), XI Festival Internacional de Teatro Clásico, celebradas en Almagro, en septiembre de 1988. Decido editarlas ahora, con ocasión del 450 aniversario de la muerte de Fernando de Rojas.

1 Marcelino Menendez Pelayo, Origenes de la novela. III, Madrid, Bailly-Bailliere, NBAE, 1915; M." Rosa LIDA DE MALKIEL, La originalidad artística de "La Celestina", Buenos Aires, EUDEBA, 1962; Marcel BATAIllon, "La Celestina" selon Fernando de Rojas, París, Didier, 1961; Pierre HeugAs, "La Celestina" et sa descendence directe, Burdeos, Institut d'Etudes Ibériques, 1973. 
que ocurrió en el teatro religioso ${ }^{2}$. La Celestina ofrecía efectivamente un modelo, réconocido y prestigiado, de enormes posibilidades e incitaciones dramáticas. Presentaba una trama perfecta y cerrada, unos personajes profundamente construidos como caracteres, una amplia variedad de situaciones dramáticas y un riquísimo diálogo y lenguaje literario. Todo ello resultaba del mayor atractivo para los dramaturgos del siglo XVI, faltos, como estaban, de una consistente tradición dramática, escasos de argumentos y recursos teatrales y deslumbrados por la inmensa popularidad de la Tragicomedia. A ella acudirán reiteradamente en busca de inspiración a la hora de montar sus espectáculos representables.

Pero esta nueva situación de la representabilidad de las obras es la que va a determinar de manera decisiva el modo y proceso de imitación. Los dramaturgos quinientistas, que sí conciben sus piezas para que sean montadas sobre las tablas - en la corte de palacio, en el escenario público o en el carro procesional, según los casos-, se verán obligados a acomodar el modelo a esas nuevas necesidades. Éste sólo podrá funcionar entonces de un modo parcial, reductivo y a veces, si se quiere, simplemente anecdótico. La complejidad y extensión de La Celestina hará inviable una imitación, digamos, plena en el teatro. En cambio, cuando ese tipo de imitación llegue a producirse, lo hará en molde genérico distinto, lo que terminará configurando esa nutrida serie literaria de la "celestinesca" a que nos referíamos al principio.

La imitación parcial y representable que ejercitan nuestros dramaturgos del XVI supondrá, ante todo, una drástica reducción y esquematización del modelo. Habitualmente se imitará sólo un personaje aislado o un grupo de personajes (la tercera, la pareja de amantes, los criados), nunca el repertorio completo, y sí siempre convertidos más bien en tipos y desprovistos de su condición de caracteres. La trama argumental, por su parte, será igualmente simplificada y reducida a pura "comedia» con final feliz, renunciándose, en consecuencia, al desenlace trágico y a la compleja mixtura del expediente

${ }^{2}$ Esta sería materia de un estudio independiente, que no es posible abordar aquí. Huellas de La Celestina pueden rastrearse en las farsas de Diego Sánchez (en la Farsa de la hechicera o en la Farsa theologal, por ejemplo), en piezas del Códice de autos viejos y del llamado Códice de 1590, o incluso en una pieza de sentido moral y argumento biblico como la famosa Comedia pródiga del placentino Luis de Miranda. Con aportaciones incidentales sobre el asunto, pueden verse los siguientes trabajos: Frida WEBER DE KURLAT, «Relaciones literarias. La Celestina, Diego Sánchez de Badajoz y Gil Vicente», PhQ. 51 (1972), 105-122; Miguel Ángel PÉrEz Priego, El teatro de Diego Sánchez de Badajoz, Cáceres, Universidad de Extremadura, 1982, pp. 179-83, y Códice de autos viejos (Selección). Madrid, Castalia, 1988; Carmelo SamonÁ, "Una reminiscenza della Celestina nell'Auto de los desposorios de Joseph», en Aspetti e problemi delle letterature iberiche. Studi offerti a Franco Meregalli, Roma, Bulzoni, 1981, 353-58; Louise Fothergill-PAyne, «La cambiante faz de La Celestina (Cinco adaptaciones de fines del siglo XVI)», Celestinesca, 8 (1984), 29-41, y "Celestina transformada en figura teatral", Jherorromania, 23 (1986), 149-55. 
de «tragicomedia» a que había tenido que recurrir Fernando de Rojas. La imitación de las situaciones dramáticas se producirá también de forma aislada y circunstancial: se mantendrá siempre el escenario urbano, pero se escamotearán las escenas prostibularias, y será muy variable y diversa la imitación de episodios particulares, tales como las entrevistas de los amantes, sus quejas de amores, el ir y venir de criados, las intervenciones y conjuros de la tercera, etc.

En cuanto al lenguaje literario y teatral, el modelo generalizará el empleo del diálogo de réplicas breves, de monólogos y de apartes. Queda excluido, en cambio, el diálogo oratorio, mientras que el diálogo de largos parlamentos y réplicas breves se recluye prácticamente en la escena de las quejas amorosas de los amantes ante el criado confidente o en la situación muy repetida y característica de las invectivas anti y profeministas, casi siempre en boca de criados y repletas de alusiones cultas (como, por ejemplo, en las comedias Ypólita y Tidea). Asimismo, será abundante el uso de refranes y sentencias y, muchas veces, el tuteo característico del modelo. Con todo, la densidad y riqueza del lenguaje celestinesco quedará extraordinariamente mermada y simplificada, aunque ciertamente no dejará de ganar en agilidad y viveza, gracias sobre todo al verso de arte menor en que ahora están escritas las obras, que, como daba a entender Juan Timoneda al justificar sus propias comedias, las hace mucho más aptas para la representación:

«... quán apazible sea el estilo cómico para leer puesto en prosa y quán propio para pintar los vicios y las virtudes, bien lo supo el que compuso los amores de Calisto y Melibea y el otro que hizo la Thebayda. Pero faltávales a estas obras para ser consumadas poderse representar, como las que hizo Bartolomé de Torres y otros en metron".

Estas obras en metro y representables son a las que nos referiremos en lo que sigue, con el propósito de estudiar el grado de influencia que sobre ellas ha ejercido La Celestina y comprobar hasta qué punto esa influencia ha acompañado o incluso determinado el desarrollo y evolución del teatro a lo largo del siglo XVI.

Una de las primeras comparecencias de motivos celestinescos en escena

${ }^{3}$ Las tres comedias del fecundisimo poeta Juan Timoneda, Valencia, 1559, ed. facsímil, Madrid, Real Academia Española, 1936. 
ocurre en la Égloga de Plácida y Vitoriano, de Juan del Encina, obra seguramente representada en Italia a comienzos de 1513, en la corte romana del cardenal de Arborea ${ }^{4}$. Aparte algún motivo no demasiado fundamentado - como puede ser el del suicidio de Plácida con relación al de Melibea-, que alguna vez se ha señalado, la imitación de la obra de Rojas se reduce en la Égloga al personaje de la tercera Eritea, calco esquemático de Celestina. Eritea es, sin embargo, como bien ha visto López Morales, un personaje prácticamente desprovisto de función en la obra, casi superfluo desde el punto de vista argumental ${ }^{5}$. En efecto, Vitoriano, el protagonista, para curarse del amor no correspondido de Plácida, aconsejado por su amigo Suplicio, recurre a los amores de Flugencia, los cuales consigue sin apenas dificultad, aunque enseguida los desdeñará para volver a su verdadera pasión por Plácida. En ese punto, conseguida fácilmente Flugencia, es cuando de manera fugaz entra en escena Eritea, presentada y justificada tipológicamente como tercera, pero que ya no tiene misión alguna que cumplir, pues no ha habido necesidad de allanar la relación amorosa de Vitoriano con Flugencia. Es por eso por lo que su intervención se reduce a mantener un breve diálogo con Flugencia, que simplemente sirve para esbozar su caracterización como tal personaje, bien conocido y quizá hasta familiar para el auditorio de la obra. En ese diálogo, en efecto, Eritea exhibe alguno de los rasgos caracterizadores del personaje celestinesco. Partera como Claudina, maestra de Celestina, va a auxiliar en el parto a una tal Febea, por cuyo hijo ya litigan un protonotario, un fraile y un boticario:

- Así se desprende de la detallada información de una carta de Stazio Gadio al marqués de Mantua: «Zovedi a VI, festa de li Tre Re, il signor Federico (...) si redusse alle XXIII hore a casa dil cardinale Arborensis, invitato da lui ad una commedia (...) Cenato adunche, si redussero tutti in una sala, ove si habea ad representare la commedia. Il predetto Reverendissimo era sedendo tra il signor Federico, posto a man dritta, et lo ambassator di Spagna a man sinistra, et molti vescovi poi a torno, tutti spagnoli; quella sala era tutta piena de gente, e più de le due parte erano spagnoli, et più putane spagnole vi erano che homini italiani, perchè la comedia fu recitata in lingua castigliana, composta da Zoanne de Lenzina, qual intervenne lui ad dir le forze et accidenti di amore; et per quanto dicono spagnoli non fu molto bella, et poco delettò al signor Federico" (texto publicado últimamente por Fabrizio CRUCIANI, Teatro nel Rinascimento. Roma 1450-1550, Roma, Bulzoni, 1983, p. 363; dio ya cuenta de él Alessandro D'Ancona, Origini del tteatro italiano, II, Turín, 1891, pp. 81-82).

3 Humberto LOPEZ MORALES, «Celestina y Eritrea: la huella de la Tragicomedia en el teatro de Encina", en "La Celestina" y su contorno social. Actas del I Congreso Internacional sobre "La Celestina", ed. M. Criado de Val, Barcelona, Hispam y Borrás, 1977, pp. 315-23. Véase también Pierre Heugas, "Sur une scène censurée: Encina et la Celestine», en Les cultures ibériques en devenir. Essais publiés en hommage à la mémoire de Marcel Bataillon (1895-1977), Paris, Fondation Singer-Polignac, 1979, pp. 397-403. 
FLUGENCIA En buen ora vengáis vos, comadre mía Eritea.

¿Qué buscáis?

¿A tal ora, dónde andáis?

ERITEA Voy a casa de Febea.

FLUGENCIA ¿A qué vais allí? Veamos.

ERITEA A barbullar cierta trampa, su preñez embarbullamos (...)

(vv. 652 y ss.)

Eritea es asimismo habilísima remendadora de virgos:

$\begin{array}{cl}\text { FLUGENCIA } & \text { Vos con sirgo } \\ & \text { le zurzirés luego el virgo, } \\ \text { que sea más que talludo. } & \text { Si quantos virgos he fecho } \\ \text { ERITEA } & \text { tantos tuviesse ducados, } \\ & \text { no cabrian hasta el techo. } \\ & \text { Hago el virgo tan estrecho } \\ \text { que van bien descalabrados } \\ \text { más de dos. } \\ \text { Esto bien lo sabéis vos... } \\ \text { (vv. } 694 \text { y ss.) }\end{array}$

y diestra ejecutora de hechizos amorosos y de conjuros:

\begin{tabular}{ll} 
ERITEA & \multicolumn{1}{c}{ ¿Y cómo os va con aquél } \\
FLUGENCIA & $\begin{array}{l}\text { a quien dimos los hechizos? } \\
\text { Eritea, burlo dél, } \\
\text { muéstromele muy cruel. }\end{array}$ \\
ERITEA & $\begin{array}{l}\text { Obraron los bevedizos. } \\
\text { Yo seguro }\end{array}$ \\
& que donde entra mi conjuro \\
& no son amores postizos.
\end{tabular}

(vv. 753-760)

Por todo ello ciertamente Eritea manifiesta un indudable parentesco con Celestina, pero la imitación no deja de resultar bastante esquemática y fugaz, por lo que bien podría decirse que el personaje ha quedado reducido a simple tipo dramático. Encina lo ha introducido seguramente para dar animación y variedad a su égloga, como amplificación cómica y colorista, 
y movido, sin duda, por el éxito de la obra de Rojas. Parece como si el poeta salmantino, en la última de sus creaciones dramáticas, hubiese sentido la necesidad de renovar el monótono mundo pastoril de la égloga, al que había venido limitando sus creaciones teatrales y del que tal vez nunca habían dejado de pesarle las críticas. Si la comedia urbana de Rojas había supuesto una rotunda novedad frente al un tanto atosigante y reiterado cuadro pastoril de la égloga, no deja de ser curioso comprobar cómo Encina, principal intérprete del género, siente al final de su carrera dramática - ya no escribiría ninguna otra pieza que conozcamos, aunque aún viviría casi otros veinte años - la necesidad de introducir en él nuevos aires, más realistas y cómicos y, muy atento a la moda literaria como estaba, rendir con ello homenaje a la obra de mayor éxito literario en ese momento, incluso en Italia, y que efectivamente apuntaba el camino por donde había de renovarse el teatro.

El ejemplo de Encina no fue aislado y, por esos mismos años, el poeta aragonés Pedro Manuel de Urrea, gran catador de modas literarias y discípulo del salmantino, se muestra también asiduo imitador de La Celestina. Aparte su Penitencia de Amor, en prosa y en la serie de la celestinesca, del mayor interés resulta su intento de poner en verso la obra de Fernando de Rojas, en una pieza que titula Égloga de la Tragicomedia de Calisto y $\mathrm{Me}$ libea, de prosa trobada en verso y que recoge en su propio Cancionero (Logroño, 1513$)^{6}$. El experimento en realidad sólo alcanza a algo menos de la mitad del primer acto: hasta el momento en que marcha Sempronio en busca de la vieja y queda solo Calisto. El texto resulta metrificado de manera casi literal, si bien con frecuentes ripios y algunas alteraciones poco significativas, como puede ejemplificar el siguiente fragmento:

\begin{tabular}{ll} 
CALiSTO & \multicolumn{1}{c}{ Veo en esto, Melibea, } \\
la gran grandeza de Dios. \\
¿ElibeA & ¿En qué, Calisto, veis vos \\
cosa que tan alta sea? & En dar poder a natura \\
CALiSTo & que de perfecta hermosura, \\
& acabada, te dotase, \\
& y a mi, que verte alcançasse \\
& sin merecer tal ventura $(. .)$.
\end{tabular}

(vv. 1-9)

- Véase Ruth House Webber, «Pedro Manuel de Urrea y La Celestina», en "La Celestina» y su contorno social..., op. cit., pp. 359-66; Robert L. HATHAWAY, «La Egloga de Calisto y Melibea de Ximénez de Urrea», NRFH, 27 (1978), 314-20. 
Lo interesante de este intento, a nuestro propósito, reside en el hecho de que de nuevo venga revestido bajo el título de égloga y con pretensiones de representabilidad, según indica la rúbrica:

"Esta égloga ha de ser hecha en dos vezes: primeramente entra Melibea y luego después Calisto, y passan allí las razones que aquí parecen, y al cabo despide Melibea a Calisto con enojo, y sálese él primero y después luego se va Melibea, y torna presto Calisto muy desesperado a buscar a Sempronio, su criado, y los dos quedan hablando hasta que Sempronio va a buscar a Celestina para dar remedio a su amo Calisto. Está trobado hasta que queda solo Calisto y allí acaba, y por no quedar mal, vanse cantando el villancico que está al cabo".

Es hasta probable que la pieza se representara en alguna ocasión en el palacio de los condes de Aranda, puesto que va dedicada a la condesa, madre del poeta. Que Urrea, sin duda a ejemplo de Encina, advirtió también la misma posibilidad de renovar el mundo de la égloga mediante la incorporación de materia celestinesca, lo prueba además el hecho de que en la segunda de sus cuatro Églogas, publicadas en 1516 y dadas a conocer modernamente por Eugenio Asensio ${ }^{7}$, introdujera asimismo de manera episódica el personaje de la vieja tercera, que incluso de forma expresa se confiesa descendiente del modelo famoso, si no en artes hechiceriles, si en cuanto a sus dotes de persuasión y su habla aduladora:

VIEJA ¿Y no sabes tú que soy
hermana de Celestina,
y que soy yo muy más fina,
que sabemos ya más hoy?
Donde quiere que yo voy,
aunque no soy hechizera,
con mi lengua lisongera
todo quanto quiero doy.

(vv. 161-68)

Un nuevo paso en la imitación dramática de La Celestina supone la obra

${ }^{7}$ Pedro Manuel de URReA, Églogas dramáticas y poesías desconocidas, ed. E. Asensio, Madrid, Col. Joyas Bibliográficas, 1950. 
de Torres Naharro, especialmente su comedia Himenea, la pieza en que tal vez queda mejor plasmada la fórmula dramática ensayada por el autor. La crítica, en efecto, ha subrayado siempre la filiación celestinesca de la comedia, y con aquel modelo ha relacionado, por ejemplo, la pareja de amantes, Himeneo y Febea, de noble linaje y enamorados tras un súbito encuentro, o los dos criados, Eliso y Boreas, el primero más fiel a su amo y el segundo más cínico y taimado, a los cuales recompensa Himeneo, aquí también con "saya y jubón», tras su éxito amoroso. Asimismo se ha advertido un influjo parcial de los actos XII, XIV y XV de La Celestina en la acción de la obra, en episodios como el de la entrevista nocturna de los amantes y la cita para la noche siguiente, la huida de los criados debido a los ruidos que oyen en la calle, la interrupción brusca de la entrevista y la salida precipitada del galán, etc. ${ }^{8}$. Ahora bien, en nuestra opinión, la influencia de La Celestina va más allá de esa serie de motivos aislados y afecta a la concepción misma de la obra.

El propósito de Naharro no ha sido otro que el de construir una comedia, esto es, conforme a su conocida definición en el proemio de la Propalladia, «un artificio ingenioso de notables y finalmente alegres acontecimientos por personas disputado». El «artificio" que efectivamente pone en marcha es el de un caso amoroso apasionado: Himeneo, enamorado de Febea, ronda su casa con serenatas y músicas y, tras entrevistarse con ella y declararle su amor, consigue que le corresponda y le admita en su casa la noche siguiente; el Marqués, hermano y guardador de Febea, está vigilante y les sorprender en esa cita; el galán huye y el Marqués se dispone a dar muerte a Febea por haber mancillado su honra y el honor familiar, aunque antes le permite confesión; Febea proclama su inocencia e Himeneo, que en realidad habia ido en busca de sus criados huidos, regresa a tiempo para declarar que siempre sus intenciones fueron honestas y que está casado por palabra con Febea; este matrimonio secreto contraría aún al Marqués, pero al fin acaba aceptando la situación y todos celebran el casamiento. El caso amoroso se resuelve, pues, felizmente y culmina con el canto de un "villancico" final que celebra esa "victoria de amores»:

Victoria, victoria, los mis vencedores, victoria en amores.

Victoria, mis ojos, cantad si llorastes,

"Véase M. Romera-Navarro, "Estudio de la Comedia Himenea de Torres Naharro", $R R, 12(1921), 50-72$. 
pues os escapastes

de tantos enojos,

de ricos despojos

seréis gozadores.

Victoria en amores.

¡Victoria, victoria!

(vv. 1688-1698)

De ese modo, queda perfectamente logrado el final feliz, el «alegre acontecimiento" con que, tal y como entendía Naharro, debía concluir toda comedia. Para la construcción del género, ciertamente podía contar Naharro con los modelos clásicos, terencianos, e incluso con la más próxima comedia humanística. Pero hay en él un deseo expreso de apartarse de los antiguos («Quiero ora decir yo mi parecer, pues el de los otros he dicho...») y crear su propia comedia. Y es en ese punto precisamente donde comienza a funcionar como referente La Celestina.

Aquel final feliz propicia un tratamiento nuevo del caso amoroso, que lo hará artificiosamente sorprendente e ingenioso, casi «esperpéntico», para emplear el término con que alguna vez caracterizó Marcel Bataillon el arte naharresco ${ }^{9}$. El punto de partida es, en efecto, como en La Celestina, un conflicto formulado aún dentro de las convenciones del amor cortesano. El amante, el caballero Himeneo, se duele de amores por su dama, a quien apenas ha tenido ocasión de conocer:

Pero en mi primer miraros

tan ciego de amor me vi

que, cuando miré por mí,

fue tarde para hablaros.

(vv. 235-238),

aunque ha bastado para que se sienta morir de amores y proclame ante ella su fervorosa adoración y servicio, enloquecido su corazón del placer del

\footnotetext{
${ }^{9}$ Marcel Bataillon, «Le Torres Naharro de Joseph E. Gillet», RPh, 21 (1967), 143-70.
} 
padecer y de la pena que aquélla le causa, tal y como expresan, en la más pura retórica cancioneril, los versos que hace cantar en su ronda:

Tan ufano está el querer con cuantos males padece, que el corazón se enloquece de placer con tan justo padecer (...)

Es más preciosa ventura vuestra pena que cualquiera gloria ajena (...)

(vv. 577-593).

Pero enseguida, en su inmediata confrontación con la realidad, el caso amoroso se aleja de esa formulación ideal. En el encuentro con la dama, ésta, Febea, no sólo ya no entiende bien el lenguaje conceptuoso del amante cortés:

No os entiendo, caballero.

Si merced queréis hacerme, más claro habéis de hablarme.

(vv. 620-622),

sino que tampoco opone apenas resistencia a las pretensiones amorosas de éste y le franquea, sin mayor obstáculo, la puerta de su casa. Incluso el patético conflicto de honra que está a punto de desencadenarse, debido a la oposición celadora del Marqués, no es, en última instancia, sino aparente y momentáneo, pues todo queda resuelto al conocerse que entre los amantes no hubo sino un matrimonio secreto, por palabra, lo que era perfectamente legítimo y concorde tanto con las normas sociales de la época como con el desenlace feliz de la comedia.

Resulta así que la única falta de los amantes ha sido la de concertar por sí solos su suerte amorosa, sin mediación ni negociación alguna, lo que ciertamente ha resultado su propia «victoria en amores», como satisfecho pregona Himeneo:

Ya sé yo poner tercero donde fuere menester, pero si tomo mujer, para mi solo la quiero.

(vv. 1586-1589), 
y celebra también Febea:

porque me supe casar

sin ayuda de parientes,

y muy bien.

(vv. 1600-1602).

Ese individualismo en amores, libre, natural y jovial, no deja de ser asimismo una sutil réplica a los planteamientos teóricos de La Celestina, donde la tercería amorosa era precisamente principal desencadenante de la tragedia.

En definitiva, creemos que Naharro ha tenido en su obra muy presente el modelo celestinesco y, con gran maestría, ha sabido verterlo en el molde de la comedia renacentista, que él mismo había fraguado en su teoría. En la comedia, el rasgo constructivo dominante no era otro que el final feliz - los «finalmente alegres acontecimientos» de su propia terminología-, y a él había que ajustar el "artificio ingenioso" de la trama. Ese final feliz es ciertamente el que impone rebajar la condición extremada, cortés, del caso amoroso; de donde, una vez situado en terreno más próximo al natural, surge la ironía del autor ante el apasionamiento de Himeneo o los tufos de honra del estrafalario Marqués. Con todo ello, aquel amor apasionado resulta perfectamente realizable, por lo que con toda facilidad puede prescindir de la tercería amorosa y romper así con la tradición literaria. Esa ausencia de la alcahueta en la obra es la que dificultaria percibir a primera vista la auténtica filiación calestinesca de la pieza de Naharro.

Conforme al modelo instaurado por la Propalladia en 1517, se escribieron, en esa primera mitad del siglo XVI, diversas piezas teatrales que configuran todo un género de comedia novelesca o de enredo. En ellas es también eficazmente operativo el modelo celestinesco, si bien igualmente troquelado en el molde de la comedia y el final feliz.

La primera de esas imitaciones es seguramente la Comedia Ypólita, de autor anónimo, publicada, junto a las celestinescas imitaciones en prosa Thebaida y Seraphina, en Valencia, por Jorge Costilla, en 1521. De su filiación celestinesca da cuenta ya el hecho de que salga a la luz acompañando a esas otras dos imitaciones de descendencia directa, aunque se diferencia 
de ellas en su más breve extensión, en que está escrita en verso y en su condición más teatral y representable ${ }^{10}$.

La Ypólita, calificada severamente por Moratín de "farsa indecente», plantea también un conflicto de amores entre dos nobles enamorados, Ypólito y Florinda, con la intervención asimismo de sus respectivos criados: Solento, Jacinto y Carpento, de la parte del galán, y Solisico, mozo de pocos años, de la de la dama. El caso se resuelve aquí sin apenas intriga ni peripecia. Los dos protagonistas manifiestan abiertamente desde el principio su mutuo enamoramiento, y los criados apenas si tienen que intervenir como mediadores para concertar la cita amorosa y, eso sí, no dejar de recibir sus regalos de recompensa. Todo, desde el primer momento, apunta a ese final feliz: no hay obstáculo alguno que se cruce entre los amantes, quienes manifiestan compartir un amor correspondido, hasta el punto de que tendrán que ser los servidores Solento y Solisico los que introduzcan una sombra de reflexión sobre los peligros para la honra y fama de Florinda.

De La Celestina procede el esquema inicial de los personajes y sus comportamientos en la obra: el amante Ypólito que, como indica el argumento en prosa, "se enamoró en demasiada manera»; la doncella Florinda, "nacida de illustre familia» (aunque "huérfana de padre», lo que también viene a suponer una cierta simplificación de la trama); y las figuras mediadoras de los criados, algo taimados y desleales, aunque bastante desdibujados frente al modelo (alguno, como queda dicho, llega a asumir un tanto confusamente las funciones de confidente, tercero y hasta oponente). Y también de allí proceden numerosos motivos particulares, como las hiperbólicas quejas de los enamorados, las largas diatribas en favor y en contra del amor y de las mujeres -que ahora sostienen Solento y Jacinto-, las idas del criado mediador a casa de la doncella, la cita nocturna de los enamorados, los «brocados y sedas" de la recompensa, o los numerosos refranes y sentencias que, junto a las citas eruditas, salpican el discurso.

Sin embargo, de nuevo aquí todo ha recibido un puro tratamiento cómico, ha sido ahormado en la estricta fórmula de comedia: los amantes excesivos han podido consumar su pasión y en su entrevista amorosa, comentada lúbricamente por los criados que la contemplan como espectadores, han podido llegar a tener «cumplido efecto sus enamorados desseos». Ello supone una gozosa liberación del amante, que quiere compartir su alegría mediante la recompensa a sus criados:

${ }^{10}$ Modernamente ha sido editada por P. E. Douglas, Philadelphia, 1929. 


$\begin{array}{ll}\text { YPólito } & \text { Pues estó alegre y contento } \\ \text { y ageno de pensamiento, } \\ \text { el que bien bien me quisiere } \\ \text { no esté triste, } \\ \text { y tú, Solento, te viste } \\ \text { mañana de carmesí; } \\ \text { y de seda de cepti, } \\ \text { de la mejor que truxiste, } \\ \text { de vestir } \\ \text { corten, por bien lo cumplir, } \\ \text { a todos essos criados (...) } \\ \text { Assí se pasan los lodos, } \\ \text { que no contino endurando } \\ \text { y gimiendo y planteando } \\ \text { con todas formas y modos, } \\ \text { lo ques' gasta. }\end{array}$

De semejante factura literaria, bajo la inspiración a un tiempo de $\mathrm{Na}$ harro y La Celestina, son las dos comedias del dramaturgo aragonés Jaime de Huete, la Tesorina y la Vidriana, publicadas hacia $1525^{11}$. La Tesorina escenifica también un caso de amores, entre el galán Tesorino y la doncella Lucina. El galán se confiesa a su criado Pinedo y se queja de amores en un apasionado y erudito monólogo:

\author{
(...) Qual Sansón \\ por Dalila, o qual Amón \\ por Thamar, hermano infiel, \\ tuvo tan ciega passión, \\ o qual Jacob por Rachel; \\ qual Tereo,
}

$"$ Comedia intitulada Tesorina, la materia de la qual es unos amores de un penado por una señora, y otras personas adherentes. Hecha nuevamente por Jayme de Güete; pero, si por ser su natural lengua aragonesa, no fuere por muy cendrados términos, quanto a esto, merece perdón. Los interlocutores son los infrapuestos, y es de notar que el frayle es zazeador, s.l., s.i., s.a. (15281535?); Comedia llamada Vidriana, compuesta por Jayme de Güete, agora nuevamente. En la qual se recitan los amores de un cavallero y de una señora de Aragón, a cuya petición, por serles muy siervo, se ocupó en la obra presente; el sucesso y fin de cuyos amores va metaphóricamente tocado justa al processo y execución de aquéllos, s.1., s.i., s.a. (1528-1535?). Ambas comedias fueron editadas por Urban CRONAN en su Teatro español del siglo XVI, Madrid, Sociedad de Bibliófilos Madrileños, 1913. Puede verse ahora el estudio de M.* de los Ángeles Errazu COLÁs, El teatro de Jaime de Huete (Introducción a su estudio), Zaragoza, Caja de Ahorros, 1984. 
qual Poliphemo y Orpheo (...)

qual me siento

con la vida descontento,

el seso fuera de quicio,

sufriendo mayor tormento

que Yxión, Phineo y Ticio (...)

(vv. 741-755).

La doncella, guardada por su padre y vigilada por las criadas, sabe sin embargo del amor de Tesorino y lo acepta con total entrega y apasionamiento:

yo soy tu sierva, Lucina,

tú, mi señor, Tesorino.

(vv. 894-895),

aunque no sin antes haber rebajado burlonamente la retórica cortés de éste:

TESORINO Beso tus manos, señora, de rodillas por el suelo.

LUCINA

¡Ay, señor!

¿Para qué tanto favor, que otro día me hará falta?

TESORINO Más merece tu valor, pues te hizo Dios tan alta.

CITERIA

¿Qué Merlín!

LUCINA

¿Dízeslo, señor, a fin, porqu'es alta la ventana?

TESORINO ¡Figura de Seraphín!

No fue mi intención tan vana.

¡Mi señora, quán bendita es esta hora que me ha concedido Dios!

LUCINA ¿De veras? Con tal mejora muy poco os holgaréis vos.

Pero tanto,

TESORINO

que gozo ya como santo

la gloria de paraíso.

LUCINA ¿Por mi salud, que me espanto

en ver cómo habláis sin riso!

(vv. 799-820). 
Sin mayor obstáculo que el de hallar la ocasión propicia para la cita - a la que acudirá Tesorino disfrazado de fraile-, los amantes logran la consumación de sus amores, que además se encargará de legimitar el ermitaño fray Vegecio uniéndolos en matrimonio secreto. Cuando el padre, Timbreo, regresa y siente mancillada su honra, fray Vegecio sólo tiene que informarle de la legitimidad de la situación, lo que termina complaciendo a Timbreo y sirve para poner el final feliz a la comedia.

Pero además de esta ingeniosa trama amorosa, que en realidad viene a ocupar sólo una parte de la pieza, hay que advertir que la comedia sabe explotar muy eficazmente numerosos lances y recursos teatrales primitivos, como las figuras del pastor o la negra, la del fraile ceceador, así como la mezcla de sus respectivas jergas lingüísticas, las riñas y aporreos, el cambio de vestidos, etc. De raíz celestinesca son claramente la trama amorosa y los personajes de la obra: la pareja de amantes apasionados, los criados confidentes o el padre guardián y celoso de su honra. Celestinescos resultan también el citado monólogo erudito del galán quejándose de amores (vv. 730 y ss.), asi como el de Timbreo lamentándose de su deshonra contra el mundo, que no deja de recordar el modélico de Pleberio:

Mundo malo, ¿cómo, y éste es el regalo de tus cautelosas mañas, con tal desbarrar de palo que me llega a las entrañas?

¿Qué pudieras hazer, aunque más quisieras?

No estimo lo que dexaste; callara, si más me hizieras, dexando lo que llevaste (...)

Que si miras

a Minos, Niso, Ciniras, por sus hijas amenguados, si fueron tristes sus iras, muy más tristes son mis hados.

Rutiliano,

ni aquel Ceseto romano, ni Balbo, ni quantos fueron, Seleuco, ni Ariobarzano, sus hijos tanto quisieron quanto yo (...)

(vv. 2272-2322). 
Sin embargo, también aquí el caso ha sido tratado en clave de comedia: de nuevo el necesario y obligado final feliz ha desplazado al puro amor cortés irrealizable -incluso rebajándolo irónicamente, como veíamos, en las réplicas de la dama - y ha excluido también la intervención de la tercera, cuya función en cierto modo viene a asumir grotescamente el fraile legitimador.

Situación y problemas parecidos son los que presenta la comedia $\mathrm{Vi}$ driana, sólo que ahora los dos amantes, Vidriano y Leriana, comparten un amor idealizado e irreal, y son los criados quienes han de rebajar y naturalizar su condición. En claro remedo expresivo celestinesco, a Cetina, criada de Leriana, cuesta creer, por ejemplo, que Vidriano pueda morir de amores, tal y como cuenta su criado Carmento:

$\begin{array}{ll}\text { CETINA } & \begin{array}{l}\text { El primero estoy por ver } \\ \text { dessos que mueren dessa arte. } \\ \text { iNo has oído } \\ \text { CARMENTO de Biblis y de Dio, } \\ \text { de Philis por Demophón? } \\ \text { Esso tú te lo has fingido; } \\ \text { no lo creo, hablillas son. } \\ \text { iQué apostura } \\ \text { que sacas de la escriptura } \\ \text { dessas vanas poesías! }\end{array} \\ \text { CARMENTO } & \begin{array}{l}\text { iEs hablilla, por ventura, } \\ \text { la que cuentan de Macias? }\end{array}\end{array}$

(vv. 950-961)

El conflicto, por lo demás, surge ahora debido a que los padres han propuesto a Leriana otros pretendientes que ella ha ido rechazando, incluso hasta tomar la decisión de disponerse a entrar en religión. Sin embargo, basta con que Vidriano se haga presente, cuando todos van a salir hacia el convento, para que los padres acepten gustosos al amante, apenas con el ligero reproche de que no les haya comunicado antes sus intenciones, y el casamiento ponga el final feliz a la comedia:

$\begin{array}{cl}\text { LEPIDANO } & \text { Mas ipor qué sin tal afrenta } \\ \text { no nos lo hablastes primero? } & \text { Fue, señor, } \\ \text { VIDRIANO } & \begin{array}{l}\text { la causa de aqueste error, } \\ \text { aunque aora no lo excluyo, }\end{array}\end{array}$




$\begin{array}{ll} & \text { pensando que mi valor } \\ \text { no llegase al pie del tuyo. } & \text { De verdad, } \\ \text { LEPIDANO } & \text { vuestra generosidad, } \\ \text { virtud y bienes y nombre, } \\ \text { sacian mi voluntad } \\ \text { más que de ningún otro hombre. } \\ \text { Vos, muger, } \\ \text { debéis de gracias hazer } \\ \text { a la magestad de Dios, } \\ \text { pues que sin lo merecer } \\ \text { dio tal descanso a los dos. } \\ \text { Baste ya. } \\ \text { Despidámonos de acá } \\ \text { porque a nadie sea notorio. } \\ \text { Plaudite, que allá se hará } \\ \text { muy cumplido el desposorio. }\end{array}$

(vv. 2942-2963)

De todo este grupo de obras que venimos tratando, la que lleva a término una imitación más próxima y completa de La Celestina es la comedia Tidea, obra de un oscuro Francisco de las Natas, «beneficiado en la iglesia perrochial de la villa de Cuebas Rubias y en la iglesia de Sancta Cruz del lugar de Rebilla Cabriada", y publicada en 1550 , sin lugar ni imprenta ${ }^{12}$. Todos los elementos de la pieza, desde la trama a los personajes, siguen muy de cerca el modelo de La Celestina: el amante Tideo confiesa sus amores por Faustina a su criado Prudente, quien le sugiere la intervención de la vieja Beroe; ésta, tras presentarse al galán y recibir sus dádivas, va a casa de Faustina de quien consigue que ablande su corazón y concierte una cita con el amante a la medianoche. A esa cita acude, en efecto, Tideo y, cuando está junto a Faustina, que ha bajado a la calle para entregarse a sus brazos, es sorprendido por el Alguacil, que le hace preso. Los padres de Faustina,

12 Comedia llamada Tidea, compuesta por Francisco de las Natas, beneficiado de la iglesia perrochial de la villa de Cuebas Rubias y en la iglesia de Sancta Cruz del lugar de Rebilla Cabriada. En la qual se introduzen un gentil hombre cavallero llamado don Tideo, y dos criados suyos, el uno Prudente, el otro Fileno; y una vieja alcagüeta llamada Beroe, y una donzella noble llamada Faustina, con una su criada Justina; dos pastores, el uno llamado Damón, el otro Menalcas; un alguazil con sus criados; el padre y madre de la donzella, el padre Rifeo, la madre Trecia. Trátanse los amores de don Tideo con la donzella, y cómo la alcançó por interposición de aquella vieja alcagüeta $y$, en fin, por bien de paz, fueron en uno casados. Es obra graciosa y apazible, s. 1., s. i 1550 (Moratín supone una de 1535). Editada modernamente por Urban Cronan, Teatro español del siglo XVI, cit. Véase además el estudio de M. Romera-Navarro, «Observaciones sobre la Comedia Tidea», MPh, 19 (1921), 187-98. 
Rifeo y Trecia, prorrumpen a continuación en un quejumbroso lamento de sus desdichas y su deshonra.

Pero es en ese punto cuando la obra cobra un nuevo giro y se aparta del modelo celestinesco, que indefectiblemente conducía a un infeliz desenlace, lo que ciertamente era contrario a las exigencias de la comedia como tal género. Así, pues, Trecia, la madre, quiere poner remedio a aquella desastrada situación, por lo que convence a Rifeo para que llame al criado Prudente y le informe de la verdadera condición y calidad de su amo. Este resulta ser, en efecto, un noble caballero, "greciano" como el mítico Tideo, que ha estado en Alemania junto al Emperador y que ahora recorre España atraído por su fama (en este punto, no puede pasarse por alto su parecido con Berintho, el protagonista de la Thebayda, caballero mancebo, hijo del duque de Tebas, que vino a España con propósito de servir al rey y aquí fue encendido en el amor de la doncella Cantaflua...). Con todo ello queda complacido y desagraviado Rifeo, que ordena al punto sacar de prisión a Tideo y concertar el casamiento con su hija Faustina.

Envueltos en una trama más novelesca aparecen los motivos celestinescos en el llamado Auto de Clarindo, publicado sin lugar ni fecha - aunque probablemente Toledo, hacia 1535-, y de cuyo autor tampoco tenemos otra noticia que la que se lee en el encabezamiento del texto: "sacado de las obras del Captivo por Antonio Díez, librero sordo ${ }^{13}$. Argumentalmente la obra -que tiene el interés añadido de ser la primera conocida dividida en tres jornadas- pone en escena una doble historia amorosa entre dos parejas de amantes, Clarindo y Clarisa, y Felecín y Florinda, primos los cuatro, que se ven obstaculizados por la oposición de los respectivos padres de las damas, Aliano y Raimundo, quienes deciden encerrar a aquéllas en un convento. Esos amores, sin embargo, son llevados finalmente a feliz término gracias a la mediación de los criados Estor, Coristán y el bobo Pandulfo, y de una Vieja alcahueta que utiliza sus artes mágicas.

Si bien es cierto que tal argumento se aleja bastante de la obra de Fernando de Rojas, hay que reconocer que numerosas situaciones y personajes del Auto cobran únicamente sentido a partir del paradigma celestinesco. Así ocurre con el amor extremado que sufre el caballero Clarindo, que le impele

${ }_{13}$ Auto llamado Clarindo, sacado de las obras del captivo por Antonio Diez, librero sordo, y en partes añadido y enmendado. Es obra muy sentida y graciosa para se representar; va partido en tres jornadas, y las figuras que entran son las seguientes: Clarindo, cavallero; Clarisa, donzella; Floriana, criada; Florinda, dama; Antonica, criada; Estor, criado; Coristán, criado; Pandulfo, bovo; Aliano y Raymundo, padres de las damas; Felecín, cavallero; un pastor, llamado Vidal, que haz'el entrada, y entra cansado y dize, s.l., s.j., s.a. Hay edición de Adolfo BonILLA y SAN MARTín en Cinco obras dramáticas anteriores a Lope de Vega, Nueva York-París, 1912 (tirada aparte de la $R H i$, vol. 27). 
a abandonarse en manos de los mediadores y terceros. Otro tanto sucede con la intervención y conducta de los criados - entre los que aparece excesivamente recargado el personaje del bobo-, quienes sólo son movidos por interés material, conscientes de su diferente condición social frente a los amos. Y, sobre todo, cobra su sentido la presencia de una Vieja hechicera, que realiza su conjuro y por medio de él consigue el concierto de matrimonio entre los amantes, que pone el final feliz a la obra.

Como vemos, la presencia de La Celestina en esta serie de comedias de la primera mitad del siglo XVI resulta de notable importancia e interés literario. No sólo ocurre en motivos y referencias aisladas - como se ha advertido en la propia Himenea, en la Ypólita o en la Tesorina- o incluso en la práctica totalidad de la obra — como en la Tidea-, sino que, a nuestro juicio, está siempre en relación con la ejecución literaria del propio género de comedia. El inexcusable final feliz ocasionará un aparente alejamiento del modelo, del que pasa a olvidarse, sobre todo, el destino trágico de los personajes y su castigo aleccionador. El amor es ahora un sentimiento mucho más jovial y realizable, incluso con sus puntas de ironía -que no moralización-para con los amantes excesivos y su retórica cortés. El conflicto amoroso se resuelve así con bastante naturalidad, aunque necesita a veces la ayuda de algún artificioso procedimiento dramático-literario, como el casamiento secreto de palabra, la figura del fraile legitimador o la revelación de la verdadera personalidad del pretendiente. Este amor, más natural y realizable, más conforme con las convenciones sociales, llegará a excluir en una serie de obras (quizá las más naharrescas) la sombría intervención de la vieja alcahueta y hechicera. Otras obras, en cambio, se recrean con la presencia de la vieja en escena, que en algún caso (como en el Auto de Clarindo) llegará a conseguir una auténtica philocaptio por medio de su conjuro.

Con este grupo de obras, cuya cronología llega aproximadamente hasta mediados de siglo, se cierra la imitación más directa y fecunda de $\mathrm{LaCe}$ lestina como modelo genérico en el teatro ${ }^{14}$. En Lope de Rueda, aparte del

14 También pueden suponerse huellas literarias celestinescas en las perdidas Comedia llamada Clariana, nuevamente compuesta, en que se refieren por heroyco estilo los amores de un cavallero moço, llamado Clareo, con una dama noble de Valencia, dicha Clariana (...), Valencia, Juan Jofre, 1522 (mencionada por P. de Gayangos y E. de Vedia en sus anotaciones a la Historia de la Literatura Española de M. G. Ticknor, II, p. 525), Comedia Claudina, de Francisco de las Natas, s.l., s.i., 1536 (da noticia de ella F. Colón, Registrum, 15218), Farsa en coplas sobre la comedia de Calixto y Melibea, por Lope Ortiz de Stúñiga, s.I., s.i., s.a. (primer tercio Xvi?) (F. Colón, Reg., 15139), o en la recientemente localizada Comedia llamada Rosabella, nuevamente compuesta por Martín de Santander. En la qual se introduzen un cavallero, llamado 
empleo de la prosa - y fuera de vagas consideraciones sobre su sentido realista dè la comedia, o su viva y natural expresión de afectos, etc.-, no hay apenas nada específicamente celestinesco, como tampoco lo hay en la efimera comedia en prosa de su generación, inspirada en modelos italianos. Cuando Timoneda, en el prólogo de sus Tres comedias ya citado, invoca La Celestina y la Thebayda como modelos de estilo cómico en prosa, lo hace sobre todo para justificar y prestigiar su propio y personal intento: «Considerando yo esto, quise hacer comedias en prosa, de tal manera que fueren breves y representables".

Con la vuelta definitiva de la comedia en verso, en el último tercio del siglo, La Celestina pierde presencia como modelo genérico en el teatro, y sus imitaciones se hacen más esporádicas y circunstanciales, a la vez que intencionadas. Las referencias celestinescas aparecen entonces por lo general envueltas en una trama compleja de episodios novelescos y fantásticos, y cobran una interpretación moralizante o incluso alegórica. Tal ocurre con la alcahueta Teodora de la comedia El Infamador, de Juan de la Cueva, "nueva Celestina» como se la llama en el texto - y quizá alegoría de las embajadas de Felipe II a Portugal, según pretende Watson en su interpretación ${ }^{15}$-, que fracasa en su intento de conseguir a la virtuosa Eliodora y termina aleccionadoramente apaleada y arrojada de su casa por las dueñas, según cuenta el criado Ortelio:

...traía el rostro asi cual si arrastrado
fuera por riscos y ásperos abrojos,
el cabello a raíz todo cortado,
lanzando sangre por la boca y ojos (...)
Dejéla cual mandó, y como volviese
por la calle real, mi desatiento
fue tal, por darte nuevas de Teodora,
que sin pensarlo di con Eliodora.
De su casa a la calle iba saliendo
con sola su criada Felicina,
y dijo asi como me vio, riendo:
'Bien negoció la nueva Celestina'.

(vv. 131-166).

\footnotetext{
Jasminio, y dos criados, el uno un Vizcayno y el otro un Negro, y una dama llamada Rosabella, y su padre de la dama, llamado Libeo, y un hijo suyo, y un Alguazil con sus criados, y un pastor llamado Pabro. En la qual tracta de cómo el cavallero, por amores, se desposó con ella y la sacó de casa de su padre. Es muy graciosa y apazible, s.l., s.i., 1550.

is Anthony Watson, Juan de la Cueva and the Portuguese Succession, Londres, Támesis 1971. La edición de la obra, en El Infamador. Los Siete Infantes de Lara. Ejemplar poético, por F. A. de Icaza, Madrid, Clásicos Castellanos, 1962.
} 
Y ocurre especialmente en la Comedia Salvaje del extremeño Joaquín Romero de Cepeda, publicada en 1582, «en la qual - como reza su rúbricapor muy delicado estilo y artificio se descubre lo que de las alcahuetas a las honestas donzellas se les sigue, en el proceso de lo qual se hallarán muchos avisos y sentencias $\aleph^{16}$. La comedia en sus dos primeras jornadas es una imitación muy completa y fiel de La Celestina, con la puesta en escena de los amores de Anacreo, mancebo de mediano estado, y Lucrecia, hermosa y rica heredera de Arnaldo y Albina, y la intervención de la alcahueta Gabrina, que conserva casi todos los rasgos caracterizadores del modelo. Sin embargo, en las dos jornadas siguientes, se diluye en una peripecia puramente moralizadora y novelesca: por sus malas artes, Gabrina y el criado cómplice son ajusticiados, y Lucrecia huye a los bosques para consagrarse a Diana; al fin, luego de diversas y calamitosas andanzas con que purgan sus culpas todos los personajes, tendrá lugar el encuentro y reconciliación final y el concierto de casamiento.

Por lo que hasta aquí hemos visto, podriamos concluir que la imitación de La Celestina es una de las constantes del teatro del siglo XVI en su evolución y que ha pasado al menos por tres momentos diferentes. Primero, con el último Encina y su seguidor Urrea, el dato celestinesco se experimenta como motivo renovador de la égloga. Después, con Naharro y sus imitadores, se utiliza como acicate y estímulo para la comedia, aunque tengan que simplificarse y distorsionarse trama y personajes, y haya de prescindirse de la carga conceptual del modelo. Finalmente, en el teatro del último tercio del siglo y de la sociedad postridentina, lo que interesará será la interpretación moralizante y aleccionadora de la referencia celestinesca, deliberadamente buscada. Después, quizá ya sólo los dramaturgos de talento, como Lope en su Caballero de Olmedo o tal vez Calderón en su misteriosa y hoy perdida comedia La Celestina, sean los que sepan volver desinteresadamente y como homenaje artístico al extraordinario modelo.

16 Joaquín Romero de CePedA, Obras, Sevilla 1582. 